\title{
ARRIVING AT OPTIMAL COST FOR A SUSTAINABLE PRODUCT USING AN INTEGRATED LCA-SCM MODEL
}

\author{
Suparno Bhatta ${ }^{1}$, Debanjana Chakraborty ${ }^{2}$, Poovammal $E^{3}$ \\ ${ }^{1,2,3}$ Department of Computer Science and Engineering, SRM Institute of Science and Technology, Kattankulathur, India, Chennai \\ 603203 \\ 1iamsuparno@gmail.com, ${ }^{2}$ chakraborty_debanjana@yahoo.com, ${ }^{3}$ poovamme@srmist.edu.in
}

\begin{abstract}
Globalization has unleashed a new era of prosperity in economic terms. This has completely changed our outlook towards lifestyle. The recent surge of consumption in the past few decades has led to the escalation in the production of goods which in turn puts a huge burden on the environment. The increasing over consumption of resources has created a sense of urgency to track the level of expenditure as well emissions from a product. One of the major concerns related to the development of green products is the cost factor that comes into play while sourcing the alternate green materials. Identifying the alternate green material increases the overall manufacturing cost for the company. There are a lot of Life Cycle Assessment (LCA) models that look into the environmental quality of a product. Similarly, there are many Supply Chain Management (SCM) models that look into the cost of the product. However very few have researched the combination of both LCA and SCM. There is a need to establish a balance between the cost and the environmental quality of a product. This paper investigates the cost of manufacturing sustainable products by looking into existing LCA and SCM models.
\end{abstract}

Keywords: Big Data Analytics, Environmental Analysis, Green Materials, Pollution Control, Life Cycle Assessment, Supply Chain Management..

\section{Introduction}

Globalization has had a huge impact and effect on innovation, communication, technology, and lifestyle. The recent surge of consumption in the past few decades has led to the escalation in the production of goods which in turn puts a huge burden on the environment. The escalation in the commutation of people and transportation of raw materials has led to a towering consumption of fuel that has led to an increase in the pollution levels in the environment. The rise in industrialization due to globalization has led to air, water, land, radioactive, noise, light, and thermal pollution. This has resulted in an unregulated rise in prices of products and services thereby plummeting a dent in the consumption and expenditure, allowing dominance of capitalism like it never has before.
In commercial terms, a supply chain is a bureaucracy of information, people, events, organizations, and resources which necessitates in supplying a product or service to a business or a customer. Supply Chain Management (SCM) refers to the set of principles related to functions of planning, organizing, directing, and controlling the flow of goods and services which involves the transportation and warehousing of raw materials, work in process inventory, finished goods and as well as end to end order fulfilment from the point of origin to the point of consumption.

The raw materials which are obtained from the natural resource combined with man-made developments bloom into a complicated and useful product which may be very friendly to mankind but are responsible for the production of harmful greenhouse gases. Recent concerns amongst environmentalists have given rise to life cycle assessment that is gradually becoming an important part of the industrial process to be able to develop a safe and green product.

One of the major concerns related to the development of green products is the cost involved in replacing the raw material which produces more greenhouse gases. It is always preferred to identify alternate material in such a way that the overall cost of production should not increase much. This research tries to establish a model that could look into the concerns by developing an integrated model that would not only measure the environmental impact but would also keep track of the profit and supply chain demand of a product. This would help manufactures to identify opportunities to reduce material and energy costs from a product system.

\section{Role of Big Data Analytics for Demand} Forecasting in SCM

Whenever anything is to be forecasted or predicted general practice is to analyze the existing data. The truthiness' of the data plays a role in the accuracy of the prediction. Also, the volume of noise-less data helps in better training and hence better accuracy. The data with characteristics such as volume, variety, velocity, value and variability are called Big Data. Table I. shows different techniques used for demand forecasting in supply chain management. 
Table I. SCM Techniques in Demand Forecasting.

\begin{tabular}{|c|c|}
\hline Techniques & Remarks \\
\hline $\begin{array}{l}\text { Cluster Analysis } \\
{[1][2]}\end{array}$ & $\begin{array}{l}\text { Clustering analysis is common in the fields of } \\
\text { pattern recognition, web development and business } \\
\text { analytics. Algorithms like K-means, fuzzy clustering and } \\
\text { self-organizing maps are implemented to group similar } \\
\text { clients as regard to their conduct. } \\
\text { This helps in better classification of different } \\
\text { kinds or classes of data or materials. The shortfall of this } \\
\text { technique is to recognize and pin-point the clients and } \\
\text { groups who do not encompass a sequence or } \\
\text { arrangement as data points. }\end{array}$ \\
\hline $\begin{array}{l}\text { K-Nearest } \\
\text { Neighbour } \\
\text { (KNN) } \\
{[3]}\end{array}$ & $\begin{array}{l}\text { KNN is a category of taxonomy that brings } \\
\text { out the similarities and likeness of the particular objects } \\
\text { to its environment. These objects are also termed as } \mathrm{N} \\
\text { attributes. Each object ties or corresponds to a place in } \mathrm{N} \\
\text { dimensional space. } \\
\text { It identifies K objects that are nearest to the } \\
\text { demarcated object. These aids in the creation of groups } \\
\text { or clusters that have likely objects. } \\
\text { - } \\
\text { analysis of automobile spare parts in its supply chain and } \\
\text { in the planning of Walmart supply chain. }\end{array}$ \\
\hline $\begin{array}{l}\text { Regression } \\
\text { Analysis } \\
{[4][5]}\end{array}$ & $\begin{array}{l}\text { Regression Analysis generates continuous } \\
\text { value functions which are used for prediction. It predicts } \\
\text { the value of a dependent variable to one or more } \\
\text { independent variables. } \\
\text { - The different types of regression are Linear, } \\
\text { Multiple, Logistic, Weighted, Random, Polynomial, } \\
\text { Non-parametric \& Robust. Simple Moving Average } \\
\text { model, Multiple Linear Regression. } \\
\text { - Symbolic Regression has been used with } \\
\text { genetic programming which resulted in Symbolic } \\
\text { Regression coming out as first. } \\
\text { - } \quad \text { Regression and Neural Networks can be } \\
\text { beneficial if it is used for forecasting the demand of } \\
\text { perishable products if the sales numbers are known } \\
\text { within the first few hours of the day. }\end{array}$ \\
\hline $\begin{array}{l}\text { Support Vector } \\
\text { Regression } \\
\text { (SVR) } \\
{[6][7]}\end{array}$ & $\begin{array}{l}\text { Support Vector Machine is the methodology } \\
\text { which is implemented by nonlinear mapping to convert a } \\
\text { training dataset into a higher dimension of data classes. } \\
\text { - } \quad \text { It seeks the optimal separating hyperplane } \\
\text { which separates the resulting class from another. Supply } \\
\text { chains related to household and personal care have used } \\
\text { SVMs for demand forecasting. } \\
\text { - Particle swarm optimization has been used } \\
\text { with SVM to get a better separating hyperplane which } \\
\text { classifies sale data and demand forecast in each } \\
\text { cluster. It is the implementation of regression in SVMs. } \\
\text { The logic of SVR is the usage of a linear regression } \\
\text { function in a high dimensional feature. It is commonly } \\
\text { used in Financial \& Cost Prediction purposes, } \\
\text { identification of objects, speaker and handwriting. } \\
\text { - Thus, it results in an increased accuracy. The } \\
\text { only disadvantage is that SVRs work on problems } \\
\text { regarding estimation and normal vs anomaly detection. } \\
\text { - } \\
\text { optimization and genetic algorithms. While configuring } \\
\text { the parameters of SVR, this approach was tested with the } \\
\text { accuracy of Mean Absolute Percentage Error and it } \\
\text { showed an extremely high insight by particle swarm } \\
\text { optimization with respect to time intensity and Mean } \\
\text { Absolute Percentage Error. }\end{array}$ \\
\hline
\end{tabular}

\section{Challenges faced in using Big Data}

Companies might find leveraging cloud computing as a financial burden however data quality issues are often related to the process of data generation. Supply chain managers would find it difficult to work with data of poor quality as they rely on insights based on past data. There should be absolute completeness, consistency, accuracy and timeliness, relevancy, value, quantity, accessibility and reputation of data dimensions. In demand forecasting, most of the time is given to endogenous time complex variables and not exogenous data which has shown results of giving better insights. There is a lack of

accuracy of forecasting in the supply chain due to lack of techniques available to forecast enhanced supply chain operations.

Predictive analytics is very tedious which includes different stages of development and testing. It is important to have proficient specialists of different mindsets to finish various tasks. There is a significant lack of information technology resources across companies in the supply chain network which can cause challenges in real time. The challenges which could arise in making a multidisciplinary team can be principal agent conflicts, data sharing policies, incentive arrangements. There are major hindrances in data sharing due to outdated regulations. Security laws of data could be a major problem for multinational supply chains who are bound by laws of different countries when sharing data across the logistic chain. It is demanding to implement real time data because the organization may react to minor changes excessively which worsens the bullwhip effect by increasing the risk in supply chain and price of warehousing. Big Data Analytics focuses on solving problems not on causation but on correlation. Indistinct profits and vagueness on the return of investment makes the investors concerned about implementing Big Data Analytics into their system.

\section{Life Cycle Assessment Models}

Life Cycle Assessment (LCA) [8] refers to assessment and evaluation of the lifespan of a product in terms of quality, cost, efficiency, risk, environmental and ecological factors. The ISO 14040 and ISO 4044 has divided the assessment process in 4 major steps:

a) Goal and Scope focuses on the definition or purpose of life cycle assessment. It focuses on identifying the functional unit that should be used to measure the environment impact.

b) Inventory Analysis is used to establish an inventor that is essential for data collection. This is a necessary factor for providing us raw details on the process or action that is going to take place.

c) Impact Assessment is used for evaluating the inventory data and understanding the respective impact the set of data can have on the material. 
d) Finally, Interpretation/Discussion helps in identification of significant issues, limitations and results. The detailed analysis helps the stakeholders, producers, manufactures and consumers to make a decision about the product.

The concept of LCA came into existence in the late 1960's. Since then, a large number of models have been created with different attributes. Table II. talks about different assessment techniques that not just focus on emissions alone, but also look into the energy, risk and cost factor.

Table II. Techniques in Life Cycle Assessment Model.

\begin{tabular}{|c|c|}
\hline $\begin{array}{l}\text { PROPOSED } \\
\text { MODEL }\end{array}$ & METHODOLOGY \\
\hline $\begin{array}{l}\text { Process based } \\
\text { LCA } \\
{[9][10]}\end{array}$ & $\begin{array}{l}\text { - Identifies the input and analyses the } \\
\text { actual process of the input. } \\
\text { - Follows the ISO } 14040 \text { and ISO } 4044 \\
\text { standard mentioned above to identify individual } \\
\text { issues and looks into details of specific } \\
\text { products. } \\
\text { - Here the impact stage analyses the } \\
\text { inventory output using midpoint indicator and } \\
\text { end point indicator. }\end{array}$ \\
\hline $\begin{array}{l}\text { Economic Input/ } \\
\text { Output } \\
{[11]}\end{array}$ & $\begin{array}{l}\text { Focuses on the economic factor of the } \\
\text { product by taking an input and evaluating the } \\
\text { output using matrix method. } \\
\text { - Uses linear coefficient contrast matrix } \\
\text { method to calculate the economic transaction } \\
\text { thus helps in calculating the supply chain and } \\
\text { environmental emissions simultaneously. }\end{array}$ \\
\hline $\begin{array}{l}\text { Economic Input/ } \\
\text { Output + } \\
\text { Process LCA } \\
{[12]}\end{array}$ & $\begin{array}{l}\text { - Additional column is added to the } \\
\text { matrix for measuring energy consumed and } \\
\text { environmental quality of the product. } \\
\text { - Here the output from the previous } \\
\text { industrial sector is taken as input. Each column } \\
\text { takes in energy and emission values of a product } \\
\text { as an input for each column. The row output } \\
\text { from each industry is considered as an input for } \\
\text { the other. } \\
\text { - } \\
\text { suitable for analysing the supply and demand } \\
\text { ratio of a product. }\end{array}$ \\
\hline $\begin{array}{l}\text { System Dynamic } \\
\text { Model } \\
{[13]}\end{array}$ & $\begin{array}{l}\text { Focuses on the flow or rate at which } \\
\text { the activities change by placing emphasis on the } \\
\text { stock/ level of data that is accumulated over a } \\
\text { significant time. } \\
\text { - It uses connectors to connect } \\
\text { information and inputs together thus helping to } \\
\text { regulate the flow of data. The converter helps in } \\
\text { generating an output value. } \\
\text { b It is mostly used for finding LCA of } \\
\text { building material needed in construction. This } \\
\text { method is highly precise and places special } \\
\text { emphasis on the economic and social factors of } \\
\text { the model. }\end{array}$ \\
\hline
\end{tabular}

\begin{tabular}{|c|c|}
\hline $\begin{array}{l}\text { Emission } \\
\text { Dispersion and } \\
\text { Exposure } \\
\text { Assessment } \\
\text { Model } \\
{[14][15]}\end{array}$ & $\begin{array}{l}\text { Site-specific model that helps in } \\
\text { quantifying the size of total damage by } \\
\text { combining the population density with the } \\
\text { concentration of the pollutant in a specific area. } \\
\text { Time problem is used for analysing the health } \\
\text { issue. } \\
\text { - The space problem arises when all the } \\
\text { pollutant emission is aggregated irrespective of } \\
\text { their different location specific. }\end{array}$ \\
\hline $\begin{array}{l}\text { Environmental } \\
\text { Matrix Model } \\
{[16]}\end{array}$ & $\begin{array}{l}\text { The row mostly consists of values of } \\
\text { environmental load, resource, energy } \\
\text { consumption and waste. Whereas the column } \\
\text { consists of values obtained from the different } \\
\text { phases namely raw material, production, } \\
\text { manufacture and use/disposal phase. } \\
\text { Does not give attention to the } \\
\text { individual environment stressor i.e., the factors } \\
\text { that affect the environment which again can } \\
\text { bring about a change in the original value. } \\
\text { - Consist of range of value based on } \\
\text { quality and reducing impact ( } 0 \text { is used for } \\
\text { products that generate significant quantities of } \\
\text { hazard/toxic gas during a phase. Whereas the } \\
\text { product with the rating } 4 \text { can generate no } \\
\text { harmful residue. }\end{array}$ \\
\hline $\begin{array}{l}\text { Multi Objective } \\
\text { Optimization } \\
\text { Model } \\
{[17]}\end{array}$ & $\begin{array}{l}\text { An object specific production process } \\
\text { model which uses linear and nonlinear program } \\
\text { tools for LCA by optimizing the system and } \\
\text { finding the env impact of the system. } \\
\text { - It has the capability to describe } \\
\text { complex relationship b/w diff systems. The } \\
\text { model tries to improve and optimize certain } \\
\text { factors like temp pressure to test the result. } \\
\text { - It uses a nonlinear programming } \\
\text { language to find the LCA of the product. It also } \\
\text { optimizes a lot of physical factors. }\end{array}$ \\
\hline $\begin{array}{l}\text { Knowledge } \\
\text { based } \\
\text { Approximate } \\
\text { LCA Model } \\
{[18]}\end{array}$ & $\begin{array}{l}\text { Distributed object-oriented model that } \\
\text { identify the environment impact driver and } \\
\text { product attribute by grouping the products into } \\
\text { environmental characteristics and then relate it } \\
\text { with environmental impact drivers. } \\
\text { - The modelling focuses on parts of the } \\
\text { system where it uses different designs of a single } \\
\text { product and tries to obtain the maximum } \\
\text { efficiency by reducing the cost of material and } \\
\text { increasing the environmental factor. } \\
\text { - The input of the product can vary in } \\
\text { different ranges such as: lifetime, use time, } \\
\text { energy source, power consumption, modes of } \\
\text { operation. It has been designed to work on the } \\
\text { principle that slight change in the geometry of } \\
\text { the model can have a huge effect on the } \\
\text { KALCAS value. } \\
\text { p This model operated on } 4 \text { modules: } \\
\text { product information model, product LCA model, } \\
\text { database redundancy, implementation of query } \\
\text { facility and management support. It } \\
\text { uses artificial intelligence using a back- } \\
\text { propagation algorithm to minimize learning } \\
\text { error and focus more on environmental impact. }\end{array}$ \\
\hline
\end{tabular}




\begin{tabular}{|l|l|}
\hline Neural Network & $\begin{array}{l}\text { Simplifies LCA calculation and reduce } \\
\text { [19] [20] [21] }\end{array}$ \\
modelling time by calculating the LCA of \\
a product even if complete information is \\
presently not available. \\
- Used for evaluating the result using a \\
case-based searching technique. Each impact \\
factor is stored as a case based on the simple \\
model. \\
[22] Here, the input is taken in the form \\
of characteristics of the product, material, \\
weight, feature, weight, mass and end life. The \\
output produced by the process is the \\
environmental impact factor. \\
Model
\end{tabular}

\section{Drawbacks in the Existing LCA Models}

Process based LCA is one of the earliest designed methods of analyzing the quality of product. While applying in the real world, it was noticed that it allows only specific product comparison. It is intensive and costly in nature. To remove the previous complexity an Economic Input/Output model was developed. The disadvantage to the entire model is that the data used for this process has to be considered as collective data obtained across a large area. It does not have the capability to process local/regional data separately. This was further improved by combining both the mentioned processes. The Economic Input/Output + Process LCA is a combined model focused on additional environment and energy columns. However, the model once again did not focus on local data. Few more models namely System Dynamic Model, Emission Dispersion and Exposure Assessment Model were developed. They were much more precise and flexible compared to previous phase models. However, all the models are dependent on the accuracy of the data. The sensitivity of the meteorological parameters is not analyzed in the Emission Dispersion and Exposure Assessment Model. This process neglects the fact that different emissions take place in different regions. The Environment matrix model faces difficulty in using the model for complicated testing and processes and can lead to several manual errors. While using Multi objective optimization model users that lack knowledge of nonlinear programs face difficulty in using this model. It is a bit complicated and very selective in nature.

The Knowledge based approximate LCA model is a very sensitive model. A slight change in value can affect the entire model result. Neural Network simplifies large numbers of LCA calculations but the result of a product with new data is completely dependent on the availability of previous data. It doesn't take in consideration all data of LCA. It just focuses on specific problems. In Spite of removing a large number of traditional limits, the data used in Modular LCA depends on the accuracy of the initial data. So, any uncertainty in the initial phase can give an inaccurate result.

The information for data used in multiple processes is different for different operations of a single product. The model needs to place further emphasis on technical and logical processes. In the logical phase, new patterns of consumption and emission is noticed. In the technical process, one needs to develop a better mathematical model with increased accuracy.

\section{Existing Integrated LCA-SCM Models}

The integrated model is basically the amalgamation of the Supply Chain Management Analytics and Life Cycle Assessment. These two technologies are used to make analysis on how companies can manufacture a product more cost effective and more globally sustainable and green product which emits less carbon footprints. Few integrated models have been developed in the past.

\section{A. Integrated Modular}

This model [21] can reveal the relative importance of supplier generated impacts with respect to the pollution impact from industry due to manufacturing. Further developments are needed in cleansing the simulation model to ease what-if analysis, the trade-offs between the operative and sustainability performance and in explication of interdependency among critical processes and improvement actions and sustainability dimensions. There is a lack of 
methodologies to exactly identify optimal cost with less pollution.

\section{B. Economic Input-Output Analysis}

The environmental impact of all the different input can be assessed once all the input associated with some industrial output is traced by this method [22]. It can be used by individual companies for their products. This method has a difficulty of differentiating product types and processes used in any specific industry.

\section{Computer Aided Process}

This model [23] smoothly enables data exchange across supply chains but it is mostly difficult to gather data and has less software dependability. The future work includes finishing design and implementation of the XML-based web services for LCA data interchange and running experiments.

\section{Model Proposed}

Most companies just want to reduce the cost of material, import and manufacturing rather than the sustainability and checking out the greenhouse and carbon emissions from their product. Based on previous observations of all the independent LCA and SCM modules, one needs to develop an integrated structure that would focus on improving the cost and quality right from the raw phase. There are very few integrated models which have been worked upon previously like the Integrated Modular LCA-SCA [21], Economic input/output (EIO) analysis [20] and Computer Aided Process Engineering Applications to Environmental LCA and SCM [23]. It is necessary to bring about a significant change from the start, thus resulting in a modified and optimized version of the product.

\section{Database Collection}

Before implementation, it is important to collect relevant data that is essential to understand the feasibility of the model. The collection procedure for LCA is different from SCM phase. In this model the data collection for LCA only focuses on partial product life cycle assessment which include the Raw Material, Managing and Packaging. This is known as Cradle to Gate phase. The values collected for LCA focus on the amount of energy consumed during the production of the material. The energy consumption depends on the procedure/process used in manufacturing of the materials, types of non-renewable resources used, and transportation of the raw materials. The pollutant emission values is the data set helps us understand the quality of the product and whether it is suitable or harmful for the environment

Whereas the data for supply chain analytics for any company should be done keeping Procurement, Logistics, Demand Chain phases in mind. Here the data set focuses on acquiring the net expenditure done by the manufacturer's thus understanding the cost of expenditure in manufacturing. Gross expenditure by the company to acquire the material from the manufacturer helps us understand the profit of the product. Sometimes the Demand Forecasting of a product may depend on additional expenses like government tax or company expenditure. These data also play an important role in causing a slight change in value.

\section{9. $\quad$ Proposed Architecture}

Our model places emphasis on the first step of making a product i.e., improving raw materials. Fig. 1. is an integrated model that has been subdivided in 4 major phases: It first identifies the list of all the elements that have been requested by their customer. Based on the raw materials that are used to make the element, it will identify the emission rate of pollutants, natural resources used, total energy consumed and total sales of raw material in manufacturing the material. Once the list of all the different types of that single material is obtained, the materials are sent simultaneously into two new phases which are analyzed using the different regression techniques. Python Google Collaboratory will be used for implementation.

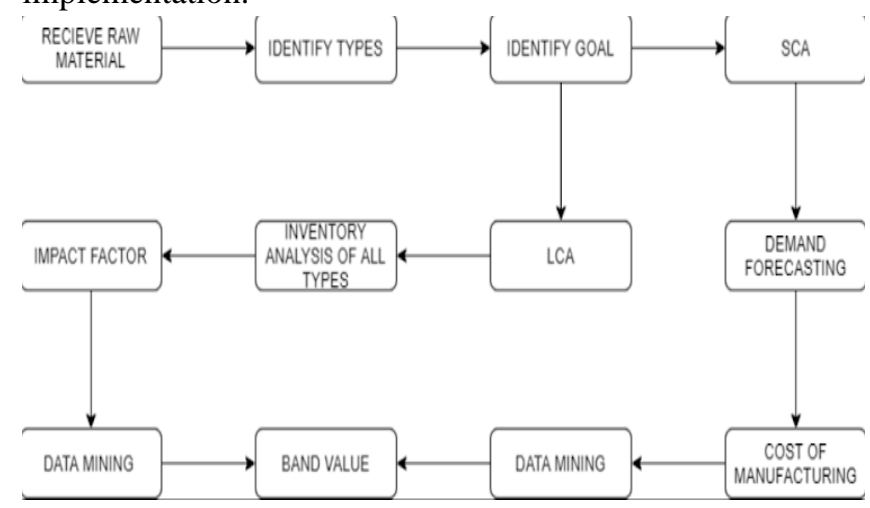

Fig. I. Architecture Diagram

\section{Implementation}

\section{A. LCA Phase}

Here the environmental quality of each raw material is tested based on the amount of pollutant emission during the manufacturing process. Initially the companies under evaluation are individually tested for the energy consumption during the construction/ manufacturing phase and transportation phase. Both the phases are also responsible for greenhouse gas emission the extraction of raw materials for the product often involves lot of energy consumption and excessive emission of harmful pollutants. This data helps us calculate the impact factor on the quantity of non-renewable resources exploited during the process. Finally, the emissions from each company are classified depending on their effects on climate change, health impacts, greenhouse emission and ecological damages on emission, climate change, greenhouse gases. Once the impact factors are identified, a conclusion is 
drawn on the environmental quality of the product.

\section{B. SCM Phase}

Simultaneously the data is then analysed for the cost factor of the product. It first enters the planning phase where a draft is made on the cost of manufacturing of the material and cost of selling the product to companies. The profit and loss is forecasted based on the above mentioned two factors. Sometimes the profit or loss value may differ depending on the additional costs such as operational cost, government tax or third-party cost. Thus, it is important to keep these data in mind during calculation of gross expenditure of the company. Once the sales data is tested for any external deviation the planning the total loss or profit of a company is observed.

\section{Data Mining Techniques Implemented}

Both LCA and SCM phase is performed using the following regression techniques. Regression technique is a supervised method that establishes a relationship between target and independent variable. The goal is to predict the amount of change based on the independent criteria of a product available. That enables to establish a trend between Energy Consumption, Sales, and Emissions in the manufacturing process using regression. During this study Linear, Huber, and Ridge Regression techniques are being implemented for a comparative study to understand which works best in this case in terms of accuracy.

a) Linear Regression: Helps in predicting the net profit/loss of a company based on the sale of the raw materials for manufacture purpose. It gives good results for predictive analysis where we have 1 dependent and 1 independent variable. As it's good for forecasting effect, and determining the strength of the predictor.

b) Huber Regression: Huber regression is a regression technique that is robust to outliers. It uses a different loss function compared to the usual least square method. It seems usual to have the least squares penalty for little residuals of loss but on big residuals, its penalty is lesser and it linearly surges rather than quadratically. Hence, it works well for datasets having enormous outliers.

c) Ridge Regression: Ridge Regression analyzes multiple regression data that has severe multicollinearity. Least squares method estimates are unbiased when multicollinearity occurs but their variances are huge that can mean that it may be far from the true value. It reduces the standard errors by adding a degree of bias to the regression estimates.

\section{Conclusion}

One of the major problems faced in the proposed model was data collection. Most of the unexplored data provides us with an abundance of information which is not adequately utilized. It has become very important for us to understand and develop models and methods that can resolve the issue of abundance of unused data. When a study is taking place, it is often a tendency to eliminate some least cost data which at the time of investigation may look insignificant but may have a huge repercussion in the calculation of environmental impact in the later stage. Another problem that is faced by the collection of data is that data and location of the raw material and other resources are often hidden by the company for confidentiality purposes. These data may have a huge impact in evaluating a life cycle assessment and cost evaluation of a product. The entire process has been executed using regression techniques as it provided a high level of accuracy during performance. The readers can also use classification techniques help manufacturer select the material that is both environmentally friendly and cost-effective.

\section{References}

[1] Murray PW, Agard B, Barajas MA. Forecasting supply chain demand by clustering customers. IFAC-PapersOnLine.2015;48(3):1834-9. https://doi.org/10.1016/J.IFACOL.2015.06.353.

[2] Pang Y, Yao B, Zhou X, Zhang Y, Xu Y, Tan Z. Hierarchical electricity time series forecasting for integrating consumption patterns analysis and aggregation consistency; 2018. In: IJCAI international joint conference on artificial intelligence; 2018, p. 3506

[3] Gaur M, Goel S, Jain E. Comparison between nearest Neighbours and Bayesian network for demand forecasting in supply chain management. In: 2015 international conference on computing for sustainable global development, INDIACom 2015, May; 2015, p. 1433-6.

[4] Merkuryeva G, Valberga A, Smirnov A. Demand forecasting in pharmaceutical supply chains: a case study. Procedia Comput Sci. 2019; 149:3-10. https://doi.org/10.1016/J.PROCS.2019.01.100.

[5] Yang CL, Sutrisno H. Short-term sales forecast of perishable goods for franchise business. In: 2018 10th international conference on knowledge and smart technology: cybernetics in the next decades, KST 2018, p. 101-5; 2018 https://doi.org/10.1109/KST.2018.8426091.

[6] M. Sarhani and A. El Afia, "Intelligent systembased support vector regression for supply chain demand forecasting," 2014 Second World Conference on Complex Systems (WCCS), Agadir, Morocco, 2014, pp. 79-83, doi: 10.1109/ICoCS.2014.7060941.

[7] Guanghui, Wang. (2012). Demand Forecasting of Supply Chain Based on Support Vector Regression Method. Procedia Engineering. 29. 280-284. 10.1016/j.proeng.2011.12.707. 
[8] Nieuwlaar, E. (2013). Life Cycle Assessment and Energy Systems. Reference Module in Earth Systems and Environmental Sciences, 3, 647-654. https://doi.org/10.1016/b978-0-12-409548-9.013348

[9] Zhichao Liu, Qiuhong Jiang, Zhang, H. (2012). Life Cycle Assessment Model: Recent Development and Future Tendency. Proceedings of the 10th International Conference on Frontiers of Design and Manufacturing, June

[10] Park, J. H., \& Seo, K.-K. (2003). Approximate life cycle assessment of product concepts using multiple regression analysis and artificial neural networks. KSME International Journal, 17(12), 1969-1976. https://doi.org/10.1007/bf02982436

[11] Carnegie Mellon University. (2016). Economic Input-Output Life Cycle Assessment - Carnegie Mellon University. http://www.eiolca.net/

[12] Matsumoto, H. (n.d.). System Dynamics Model For Life Cycle Assessment ( Lca ) Of Residential Buildings Hiroshi Matsumoto Department of Architecture and Civil Engineering, Toyohashi University of Technology Toyohashi 441-8580, Japan. Energy.

[13] Nuasaen, S., Opaprakasit, P., \& Tangboriboonrat, P. (2014). Hollow latex particles functionalized with chitosan for the removal of formaldehyde from indoor air. Carbohydrate Polymers, 101(1), 179187. https://doi.org/10.1016/j.carbpol.2013.09.059

[14] Moriguchi, Y., \& Terazono, A. (2000). A simplified model for spatially differentiated impact assessment of air emissions. International Journal of Life Cycle Assessment, 5(5), 281-286. https://doi.org/10.1007/BF02977580

[15] Hochschorner, E., \& Finnveden, G. (2003). Evaluation of two simplified life cycle assessment methods. International Journal of Life Cycle Assessment, 8(3), 119-128. https://doi.org/10.1007/BF02978456

[16] Park, J. H., \& Seo, K. K. (2006). A knowledgebased approximate life cycle assessment system for evaluating environmental impacts of product design alternatives in a collaborative design environment. Advanced Engineering Informatics, 20(2), 147154. https://doi.org/10.1016/j.aei.2005.09.003

[17] Eisenhard, J. L., \& De Schepper, M. S. (2000). Approximate Life-Cycle Assessment in Conceptual Product Design. ASME Design Engineering Technical Conferences \& Computers and Information in Engineering Conference.

[18] Chen, J. L., \& Liau, C. W. (2001). A simple life cycle assessment method for green product conceptual design. Proceedings - 2nd International Symposium on Environmentally Conscious Design and Inverse Manufacturing, 775-780 https://doi.org/10.1109/ECODIM.2001.992466

[19] Ayoub, N., Musharavati, F., Pokharel, S., \& Gabbar, H. A. (2015). Risk based life cycle assessment conceptual framework for energy supply systems in large buildings. Journal of Cleaner Production, 107, 291-309. https://doi.org/10.1016/j.jclepro.2015.04.075

[20] Brondi, C., \& Carpanzano, E. (2011). A modular framework for the LCA-based simulation of production systems. CIRP Journal of Manufacturing Science and Technology, 4(3), 305-312. https://doi.org/10.1016/j.cirpj.2011.06.006

[21] Fornasiero, R., Brondi, C., \& Collatina, D. (2017). Proposing an integrated LCA-SCM model to evaluate the sustainability of customisation strategies. International Journal of Computer Integrated Manufacturing, 00(00), 1-14. https://doi.org/10.1080/0951192X.2016.1268716

[22] Cohas, E., Hendrickson, C., Lave, L., \& Mcmichaell, F. (1995). Economic Input / Output Analysis to Aid Life Cycle Assessment of Electronics Products 1 by 2. Environmental Impacts of Electronics Product Manufacture.

[23] Barrett, W. M., Strunjaš-yoshikawa, S., \& Bell, J. H. (2007). Extension of Computer Aided Process Engineering Applications to Environmental Life Cycle Assessment and Supply Chain Management. 1187-1192. 